\title{
Prevalence and Risk Factors of Bone Spavin in Icelandic Horses in Sweden: A Radiographic Field Study
}

\author{
By P. Eksell ${ }^{1}$, M. Axelsson ${ }^{2}$, H. Broström ${ }^{2}$, B. Ronéus ${ }^{2}$, J. Häggström $^{3}$ and J. Carlsten ${ }^{1}$ \\ ${ }^{1}$ Departments of Clinical Radiology, ${ }^{2}$ Large Animal Clinical Sciences and ${ }^{3}$ Animal Physiology, Faculty of \\ Veterinary Medicine, University of Agricultural Sciences, Uppsala, Sweden.
}

\begin{abstract}
Eksell P, Axelsson M, Broström H, Ronéus B, Häggström J, Carlsten J: Prevalence and risk factors of bone spavin in icelandic horses in Sweden: A radiographic field study. Acta vet. scand. 1998, 39, 339-348. - The present field study was performed to estimate the prevalence of radiographic signs of bone spavin (RSBS) and to evaluate some possible risk factors for RSBS in the Icelandic horse in Sweden. The survey included horses from 11 farms involving 379 horses, comprising 238 geldings, 125 mares and 16 stallions. Age ranged from 0 to 19 years with a mean age of 8.1 years. Horses were radiographed with a dorsolateral-plantaromedial-oblique projection of both tarsi. Information about age, gender, origin, working intensity, number of gaits and age when saddle broken were obtained by interviewing the owners. Features of each horse's conformation were obtained by measurement or inspection.

Radiographic signs of bone spavin were found in $23 \%(n=88)$ of the horses. Horses younger than 5 years did not show any RSBS and the prevalence increased from zero to $33 \%$ between 4 and 8 years of age. Using a multivariate logistic regression model increasing age and sickle hock conformation were found to be significantly associated with increased risk of RSBS. Age when saddle broken in combination with height at the withers also influenced the multivariate logistic regression model significantly.
\end{abstract}

equine; tarsus; degenerative joint disease; bone spavin; radiology.

\section{Introduction}

The tarsus is commonly affected in horses with hind limb lameness (Vaughan 1965, O' Brien 1974, Brokken 1978, Stashak et al. 1987) and degenerative joint disease of the distal tarsal joints (bone spavin) is a common cause of tarsal disease (O'Brien 1974, Stashak et al. 1987). Bone spavin occurs in the centrodistal joint (CD), the tarsometatarsal joint (TMT) and more seldom in the proximal intertarsal joint (PIT) (Gabel 1980, Barneveld 1983, Butler et al. 1993). The lesions associated with bone spavin usually develop on the dorsomedial as- pect of tarsus and may extend further to involve most parts of the distal tarsal joints (Gabel 1980, Stashak et al. 1987). Radiographic examination is used to make an accurate diagnosis (Schebitz 1965, Stashak et al. 1987). Radiographic signs associated with bone spavin include: periarticular osteophytes (Morgan 1972, O' Brien 1974, Shelley \& Dyson 1984, Dahn \& Ueltschi 1989, Butler et al. 1993), irregular widening of the joint space ( $O^{\prime}$ Brien 1974), subchondral bone lysis or rarifications $\left(O^{\prime}\right.$ Brien 1974, Shelley \& Dyson 1984, Dahn \& 
Ueltschi 1989, Butler et al. 1993), narrowing, collapse of joint space or anchylosis (Morgan 1972, O' Brien 1974, Shelley \& Dyson 1984, Butler et al. 1993). The dorsolateral-plantaromedial oblique projection has been stated to be the most useful projection in the radiographic assessment of bone spavin (May et al. 1986, Wyn Jones 1988, Thrall 1994, Verschooten \& Schramme 1994) but no evidence was presented to support this opinion. Clinical signs reported in horses with bone spavin include lameness and stiffness which in many cases reduce the working capacity of the horse (Moyer 1978, Gabel 1980).

The disease has been suggested to be most frequent in mature horses. Type and load of work (Rooney 1969, Gabel 1980), conformation (Rooney 1969, Stashak et al. 1987) and developmental abnormalities (Gabel 1980, Hartung et al. 1983, Stashak et al. 1987, Watrous et al. 1991) have been proposed as factors predisposing to bone spavin.

Icelandic horses have become popular as leisure, trekking and competition horses and the number of registered Icelandic horses in Sweden increased from 2200 in 1990 to 7400 in 1996 (Lindberg 1998). The number of Icelandic horses diagnosed with bone spavin at the Department of Large Animal Clinical Sciences, University of Agricultural Sciences, Uppsala, Sweden increased from 2 in 1990 to 29 in 1996. Data retrieved from the largest animal insurance company in Sweden show that 7 Icelandic horses were destroyed and reimbursed due to bone spavin in 1993 and 20 in 1995 (Odenhall 1996). Other studies have shown that bone spavin is a cause of hind limb lameness in other breeds (Moyer et al. 1983, Bergsten 1983) but the prevalence of the disease in Icelandic horses in Sweden has not been assessed previously. An association between assumed predisposing factors and presence of RSBS has not been reported in Icelandic horses.
The aims of this field study was to estimate the prevalence of RSBS and further to evaluate potential risk factors for RSBS in the Swedish population of Icelandic horses.

\section{Materials and methods}

Selection of horses

Farms within $150 \mathrm{~km}$ from The Swedish University of Agricultural Sciences (SLU), Uppsala, holding a minimum of 20 Icelandic horses of which all could be radiographically examined were selected. On 8 occasions during a period of 13 months a total of 379 horses in 11 farms were examined.

\section{Protocol}

The following details were obtained from interviews with the owners and recorded for each horse: name, age and country of birth, gender, working intensity (breeding/not saddle broken, leisure, competing, trekking), number of gaits (4-gaited, 5-gaited, others) and age when saddle broken. Height at the withers was measured. Tarsal conformation was assessed by eye, with the horse viewed from the side, and classified as straight, normal or sickle (Fig.1). Skeletal type was recorded as the subjective impression of the sturdiness of the frame classified as light, intermediate or heavy.

\section{Information rate}

The gender of all horses was recorded. For other variables the information rate ranged from $81 \%$ (hock conformation) to $98 \%$ (age) (Tables 1 and 2). Information rates on tarsal conformation, body type and height at the withers varied because these variables were not included in the protocol from the beginning of the study. Information rates in some variables varied with the owner's knowledge of the history and use of the horse. 


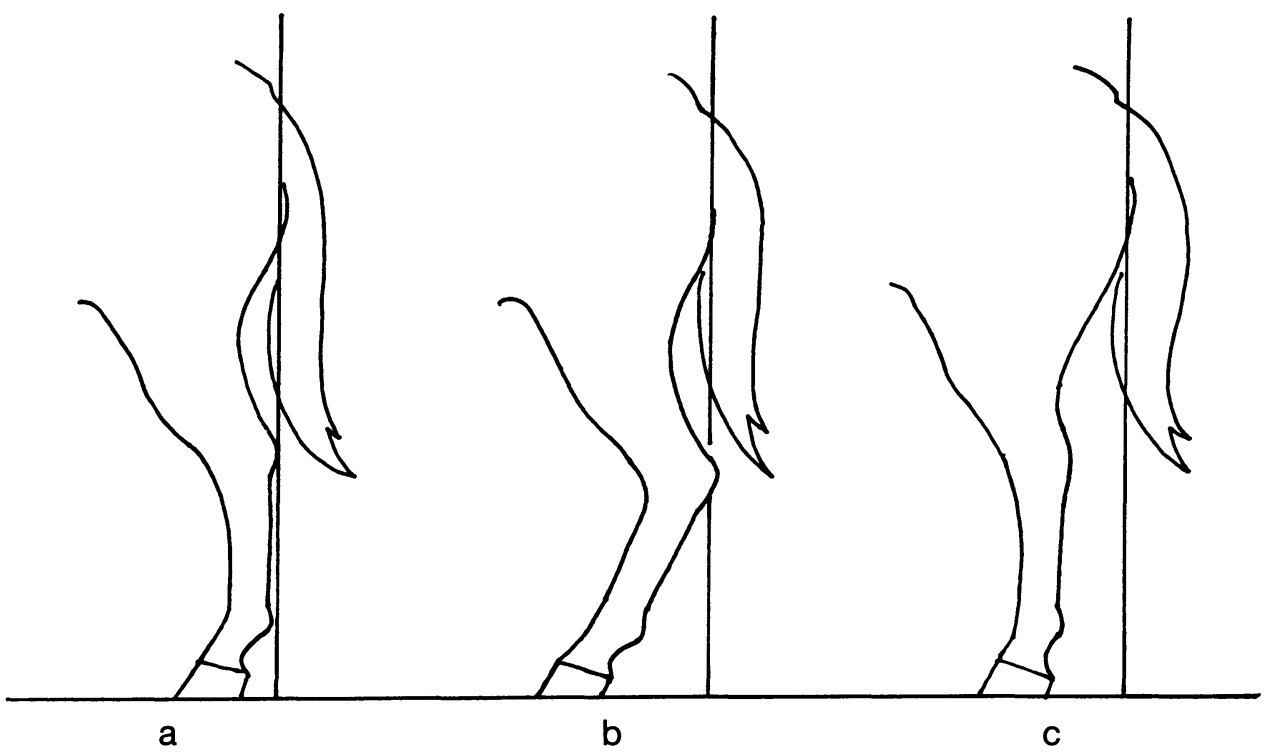

Figure 1. Schematic drawing of normal (a), sickle (b) and straight (c) tarsal conformation.

\section{Radiographic examination}

For the radiographic examination a portable $\mathrm{x}$ ray unit (Medinos 100/60, Hermansson AB, Malmö, Sweden) and developing machine (Agfa-Gevaert, Gevamatic 60, München, Germany) were used. Care was taken that the exposure settings and the latitude film (Fuji HR-L 30, Fuji Photo Film Co. Ltd, Tokyo, Japan) and screen (Kodak X-Omatic, Lanex-Regular, Rochester, NY, USA) combination used produced optimal greyscale radiographs for evaluation of subtle skeletal details. In this field study a standard dorsolateral-plantaromedial oblique (DLPIMO) view was recorded from each tarsus centred on the intertarsal and tarsometatarsal joints (Butler et al. 1993). Radiographs were coded and evaluated by 2 radiologists. Presence of radiographic signs of degenerative joint disease in the PIT, CD or TMT was used as the diagnostic criterion for RSBS. The radiographic findings were recorded after consensus of the examiners and dubious cases were always given the benefit of the doubt. To validate the method tarsi $(n=193)$ from 98 different Icelandic horses were radiographed in 4 projections (dorsoplantar, lateromedial, dorsolateral-plantaromedial oblique, plantarolateral- dorsomedial oblique) and films were evaluated according to the same criteria. It was found that the dorsolateral-plantaromedial oblique projection had a sensitivity of $93 \%$ and a specificity of $84 \%$ in detecting RSBS compared with reading all 4 projections of the same limb together.

\section{Data analyses}

The association of each potential predisposing factor with RSBS was first assessed in a screening using univariate logistic regression. Variables with a p-value less than 0.05 by the univariate analysis were entered in an initial multivariate model. All other factors were then examined further by use of multivariate logistic regression. The modelling proceeded in a for- 
Table 1. Univariate analysis of qualitative data as possible risk factors for radiographic signs of bone spavin in 379 Icelandic horses.

\begin{tabular}{|c|c|c|c|c|c|}
\hline \multirow{2}{*}{ Variables } & \multirow{2}{*}{$\begin{array}{c}\text { Information rate } \\
\text { (\%) }\end{array}$} & \multirow{2}{*}{$\mathrm{n}$ tot. } & \multicolumn{2}{|c|}{ RSBS } & \multirow{2}{*}{ p-value } \\
\hline & & & $\mathrm{n}$ & $\%$ & \\
\hline Country of birth: & 87 & & & & 0.035 \\
\hline Iceland & & 263 & 81 & 27 & \\
\hline Sweden & & 48 & 4 & 8 & \\
\hline Others & & 17 & 0 & & \\
\hline Gender: & 100 & & & & 0.0054 \\
\hline Geldings & & 237 & 68 & 29 & \\
\hline Mares & & 126 & 19 & 15 & \\
\hline Stallions & & 16 & 1 & 6 & \\
\hline Tarsal conformation: & 81 & & & & 0.001 \\
\hline Normal & & 196 & 37 & 19 & \\
\hline Straight & & 46 & 9 & 20 & \\
\hline Sickle & & 62 & 26 & 42 & \\
\hline Skeletal type: & 95 & & & & 0.74 \\
\hline Light & & 48 & 9 & 19 & \\
\hline Intermediate & & 234 & 55 & 24 & \\
\hline Heavy & & 78 & 19 & 24 & \\
\hline Working intensity: & 97 & & & & 0.0028 \\
\hline Not broken/breeding only & & 58 & 1 & 2 & \\
\hline Pleasure riding & & 98 & 29 & 30 & \\
\hline Competing & & 98 & 20 & 20 & \\
\hline Countryside trekking & & 113 & 38 & 34 & \\
\hline Gaits: & 93 & & & & 0.73 \\
\hline 5-gaiter & & 131 & 35 & 27 & \\
\hline 4-gaiter & & 196 & 49 & 25 & \\
\hline
\end{tabular}

Table 2. Univariate analysis of continuous variables as possible risk factors for radiographic signs of bone spavin in 379 Icelandic horses.

\begin{tabular}{|c|c|c|c|c|c|c|}
\hline \multirow{2}{*}{ Continuous variable } & \multirow{2}{*}{ Information rate (\%) } & \multicolumn{2}{|c|}{ RSBS } & \multicolumn{2}{|c|}{ No RSBS } & \multirow{2}{*}{ p-value } \\
\hline & & Mean & Range & Mean & Range & \\
\hline Age (yrs) & 98 & 9.6 & $5-17$ & 8.0 & $0-19$ & $<0.001$ \\
\hline Age when saddlebroken (yrs) & 89 & 4.9 & 4-7 & 5.1 & $3-14$ & 0.22 \\
\hline Height at the withers $(\mathrm{cm})$ & 86 & 135.8 & $126-147$ & 135.2 & $115-145$ & 0.27 \\
\hline
\end{tabular}

ward stepwise manner using the likelihood ratio test to determine whether a variable significantly $(\mathrm{p}<0.05)$ improved the model until the final multivariate model was determined. This multivariate model permitted evaluation of sev- eral factors simultaneously while controlling for potential confounding factors. Data on tarsal conformation was dichotomised (sickle hock: yes/no) before multivariate statistical evaluation. All uni- and multivariate modelling 
Table 3. Final multivariate logistic regression model for risk factors associated with radiographic signs of bone spavin.

\begin{tabular}{lcccc}
\hline Variable & Category & p-value* & Odds ratio & 95\% CI \\
\hline Age** & NA & 0.020 & 1.159 & $1.022-1.313$ \\
Sickle hock & Yes/No & 0.016 & 1.695 & $1.111-2.585$ \\
Age when saddlebroken** & NA & 0.044 & 0.609 & $0.352-1.052$ \\
Height at the withers** & NA & 0.958 & 0.997 & $0.904-1.100$ \\
\hline
\end{tabular}

Odds ratios and confidence intervals are for each year (Age and Age when saddlebroken) and for each $\mathrm{cm}$ (height at the withers). ${ }^{*}=$ likelihood ratio test statistics, ${ }^{* *}=$ Modelled as a continuous variable. NA $=$ not applicable, $\mathrm{CI}=$ confidence intervals.

processes for each variable were performed with the same statistical program (SAS Institute Inc. 1995) and based on the principles of Hosmer \& Lemeshow (1989). The odds ratio and confidence intervals were calculated from the estimates obtained in the multivariate regression analysis.

\section{Results}

Results from univariate and multivariate logistic regression analyses of potential risk factors associated with RSBS are summarised in Tables 1-3.

\section{Radiographic signs of bone spavin}

RSBS was found in $23 \%(n=88)$ of all horses. Radiographic changes were bilateral in $53 \%$ $(n=47)$ of the affected horses. Of 201 joints with RSBS 95\% $(n=191)$ of findings were located in the CD or TMT joints.

\section{Univariate analysis}

Effect of age, sex and origin. The material comprised 238 geldings, 125 mares and 16 stallions. The mean age of all horses was 8.1 years (range $0-19$ years). The mean age was 9.1 years $(\mathrm{SD}=3.0)$ in the geldings, 7.2 years $(\mathrm{SD}=3.1)$ in the mares, and 5.5 years $(\mathrm{SD}=$ 3.4 ) in the stallions. Geldings were significantly older than stallions $(\mathrm{p}<0.01)$. All horses younger than 5 years were without RSBS. Age significantly affected the prevalence of RSBS $(p<0.001)$ by the univariate analysis, and the prevalence of RSBS increased from zero at 4 years to $33 \%$ at 8 years of age (Fig. 2). The prevalence remained at the same level between 8 and 13 years of age and tended to decline in horses 14 years and older.

RSBS was detected in $29 \%(n=68)$ of the geldings, $15 \%(n=19)$ of the mares and in $6 \%$ $(\mathrm{n}=1)$ of the stallions $(\mathrm{p}<0.01)$. Imported horses had a higher prevalence of RSBS $(p<0.05)$ but were also significantly older $(\mathrm{p}<0.001)$.

Effect of conformation and height at the withers. Horses with sickle hocks had a prevalence of RSBS of $42 \%(n=26)$ which was significantly higher than that of horses with straight $(20 \%, n=9)$ or normal $(19 \%, n=37)$ conformation $(p<0.001)$. Bone spavin was found in $19 \%(n=9)$ of the horses with a light skeletal type, whereas lesions were identified in $23 \%(n=55)$ of those with intermediate and in $24 \%(n=19)$ of those with heavy skeletal type. The mean height at the withers was $135.2 \mathrm{~cm}$ $(\mathrm{SD}=4.2)$ in horses without RSBS and 135.8 $\mathrm{cm}(\mathrm{SD}=3.5)$ in horses with RSBS. Skeletal type and height at the withers did not influence 
the prevalence of RSBS by the univariate analysis.

Effect of age when saddle broken. Radiological evidence of bone spavin was found in $26 \%(n=50)$ of the horses broken to saddle before 6 years of age, whereas RSBS was found in $13 \%(n=4)$ in those broken to saddle at the age of 6 years or older. However, by univariate analysis, age when saddle broken did not show a significant association with RSBS ( $p>0.05$ ).

Effect of working intensity and number of gaits. The working intensity recorded at the time of the examination was significantly $(p<0.01)$ associated with RSBS. Radiographic signs of bone spavin were most frequent in horses used for pleasure riding (30\%) and horses used for trekking tours (34\%). The number of gaits the horse was recorded to be able to perform did not affect the prevalence of RSBS by the univariate analysis; RSBS was found in $27 \%(n=35)$ of horses with 5 gaits (walk, trot, gallop, toelt and pace), in $25 \%(n=49)$ of those with 4-gaits (walk, trot, gallop and toelt), and in $5 \%(n=2)$ of the remaining horses.

\section{Multivariate analysis}

Age, gender, country of birth, hock conformation and working intensity were significantly associated with RSBS by the univariate analysis (Tables 1 and 2). In the final multivariate logistic regression model (Table 3) age and hock conformation maintained a significant association with RSBS. Gender, country of birth and working intensity did not maintain any significant association with RSBS in the multivariate analysis. Age when saddle broken was also significantly associated with RSBS in the multivariate analysis but only in combination with height at the withers.

Together age, when saddle broken, and height at the withers, influenced the multivariate logis- tic regression model significantly by the likelihood ratio test and was consequently included in the final multivariate model. If hock conformation was excluded from the final model the estimates for age, age when saddle broken, and height at the withers, changed insignificantly.

\section{Discussion}

The prevalence of RSBS (23\%) found in this study is high. Especially since only unequivocal radiographic lesions were included to make positive diagnosis. Due to an increasing number of cases of bone spavin in the Icelandic horses in Sweden reported at The Department of Large Animal Clinical Sciences (SLU), and an animal insurance company (Odenhall 1996) this field study was designed to estimate the prevalence of the disease in the Swedish population of Icelandic horses. One aim was to obtain a sample size of at least 350 horses, but time and money restricted the efforts to a minimum of intense occasions. Horseowners accepted to participate in the study and a minimum of interruption of the daily routine because of the examinations was agreed upon. The DLPIMO projection has been suggested to be the most useful projection in the radiographic assessment of bone spavin (May et al. 1986, Wyn Jones 1988, Thrall 1994, Verschooten \& Schramme 1994) and was therefore concidered to be the reasonable compromise between quality of result on one hand and time consumption and radiation safety on the other. The sensitivity and specificity of the single DLPIMO projection used in this field study was regarded as acceptable. A set of 4 radiographic projections of each tarsi would have made the information more complete, but the validation of the method provided an estimation of the reliability of the radiographic findings. The sample size $(n=379)$ in this study was equivalent to $6.7 \%$ of the 5648 horses recorded in the 


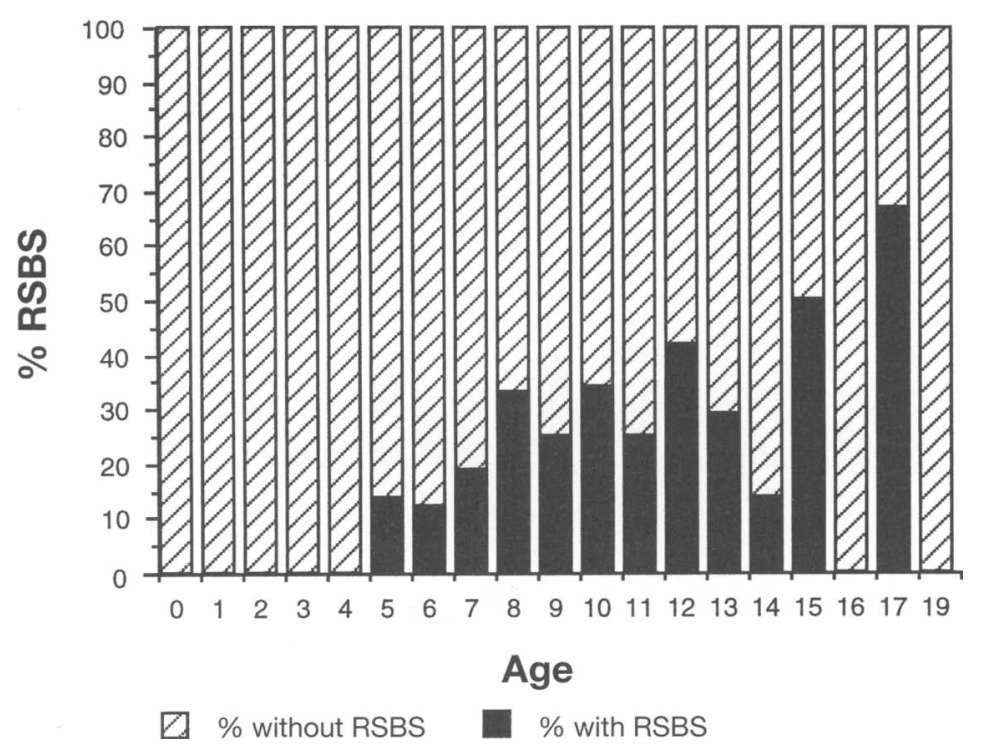

Figure 2. Proportion of horses with radiographic signs of bone spavin and age in 379 Icelandic horses.

Swedish Registry of Icelandic Horses in 1994. The registry includes most Icelandic horses in Sweden, but the exact number of Icelandic horses in Sweden is not known. The mean age of the group of horses included in this study (8.1 years) corresponded well with the mean age of the horses in the Swedish Registry of Icelandic Horses of 8.5 years in 1994 (Lindberg 1998) and the mean age of the horses in an insurance company in 1995 that was 8.9 years (Odenhall 1996). Bone spavin is previously reported to be seen most frequently in adult horses (Wyn Jones 1988). A strong association between RSBS and age was confirmed in Icelandic horses in this study. At the age of 6-12 years, when horses normally are most active, the prevalence of RSBS was $26 \%$. The prevalence of RSBS tended to decrease after the age of 14, possibly owing to loss of horses from the population due to destruction of horses with bone spavin (Odenhall 1996) but the small number of horses in this age range made estimates of changes in prevalence uncertain (Fig. 3).
The sex distribution of Swedish registered horses (Swedish Registry of Icelandic Horses, Floda, Sweden) was $21 \%$ geldings, $29 \%$ stallions and $50 \%$ mares, whereas in this study geldings predominated. This discrepancy may be explained by the fact that owners are not required to report when their colts/stallions are gelded and that many imported Icelandic horses are geldings which are not registered when entering the country.

The increase in prevalence of RSBS from zero to $33 \%$ occurs between 4 and 8 years of age coinciding with the age when most horses are broken to saddle and commencing their active career. During this period of their lives the horses are subjected to increased stress and work, factors which most likely contribute to the development of RSBS in Icelandic horses. Breaking to saddle can be performed in many different ways. Factors such as weight of the rider and the technique and intensity of the breaking should be further investigated to determine their influences on prevalence of RSBS. 


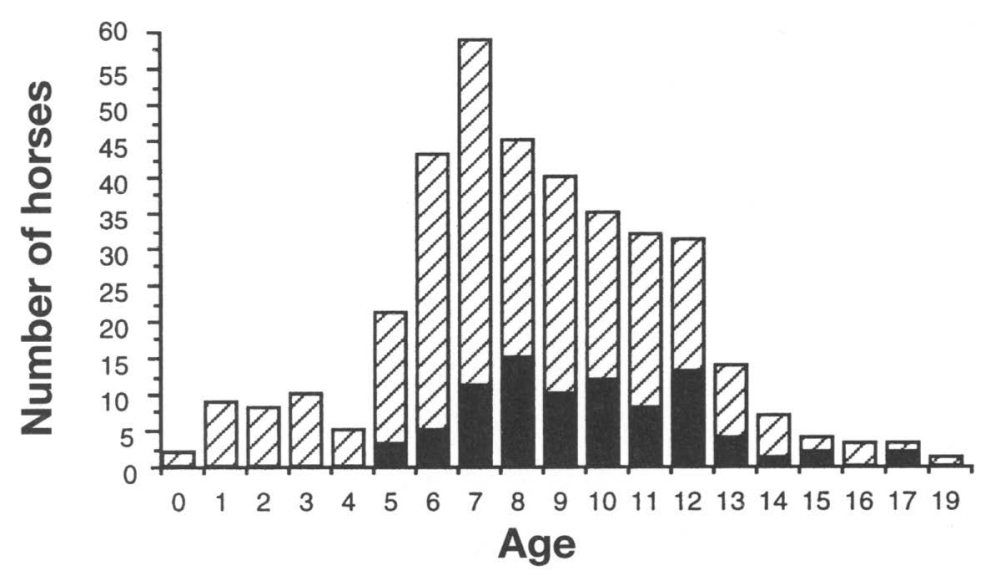

$\square$ Horses without RSBS Horses with RSBS

Figure 3. Number of horses with and without radiographic signs of bone spavin and age in 379 Icelandic horses.

Repeated stress on tarsal bones and ligaments has been suggested to be important in the development of bone spavin (Rooney 1969, Gabel 1980). In this study there was no association between working intensity and RSBS in the final multivariate logistic regression model. The recorded intensity of work was that of the time of the examination, but competing horses have normally been subjected to several years of continuous training. Also horses in the category not broken/breeding only $(n=58)$ had a mean age of only 4.8 years $(\mathrm{SD}=3.0)$ and were not likely to have been worked hard. Horses used for countryside trekking are often subjected to many hours of monotonous work many days a week, most weeks a year while pleasure riding is less hard on the horses. A complete history of each horse would be needed to fully investigate the importance of the intensity of work as a predisposing factor of RSBS. This may not always be possible since horses often change owners and type and load of work several times. Conformation in Icelandic horses is documented to be determined by a genetic predisposition (Arnason 1984). Thus the association be- tween sickle hock and RSBS found in this study indicates that genetic factors may be directly or indirectly involved in the development of the disease. Joint conformation influences limb action and thereby also the forces acting on the joint structures (Rooney 1969). This influence may explain the increase in the prevalence in RSBS at the time of increased biomechanical load in connection with saddle breaking. Future studies on hereditability may better clarify the possibility of controlling the disease by selective breeding programs.

The difference in mean height at the withers between horses with and without RSBS was small $(6 \mathrm{~mm})$. Nevertheless height at the withers in combination with age when saddle broken significantly improved the multivariate logistic regression model by the likelihood ratio test. It is possible that young tall horses give a false impression of maturity and that these horses were selected for earlier saddle breaking by their owners.

The odds ratios and the confidence intervals were calculated from the estimates given in the logistic regression calculation while the final 
multivariate model (Table 3) was determined by the likelihood ratio test. This accounted for the somewhat contradictory results given in table 3 where the $95 \%$ confidence intervals of age when saddle broken and height at the withers were not separated from 1 . Height at the withers and age when saddle broken seemed to be closely associated and only when entered into the multivariate model together the likelihood ratio of the model improved significantly $(\mathrm{p}<0.05)$.

In our experience from clinical cases there is evidence indicating that bone spavin in the Icelandic horse is a slowly progressing disease where clinical signs may precede radiographic evidence of degenerative joint disease. The onset of the disease is often followed by a period of time during which degenerative changes worsen and clinical signs of varying degrees are present continuously or intermittently. However, the progression of the disease as evaluated by radiological examination compared with clinical signs remains to be investigated as not all individuals reach the final stage of ankylosis and clinical soundness. A more complete radiographic examination with several projections of the tarsi or a more sensitive diagnostic technique such as skeletal scintigraphy may reveal evidence of bone spavin in the Icelandic horse earlier and more accurately than by the single radiographic projection used in this field study. The prevalence of RSBS in the Icelandic horses in Sweden found in this study warrants further investigations of the disease and its association to clinical signs.

\section{Conclusions}

Radiographic signs of bone spavin are very common in the Icelandic horse in Sweden. Age and hock conformation stand out as important predisposing factors associated with the presence of RSBS.

\section{Acknowledgement}

The authors thank Professor Peter Lord for linguistic advice and constructive discussions and the technicians of the Department of Clinical Radiology for excellent assistance.

This survey was supported by Försäkringsaktiebolaget Agria (Agria Insurance), Stockholm, Sweden.

\section{References}

Arnason T: Genetic studies on conformation and performance of Icelandic toelter horses. I. Estimation of non-genetic effects and genetic parameters. Acta. Agric. Scand. 1984, 34, 409-427.

Barneveld A: Spavin in the horse. University of Utrecht, Utrecht, The Netherlands, PhD Thesis, 1983.

Bergsten G: Sjukdomsfrekvenser i rörelseorganen hos ett material försäkrade hästar 1973-1981 (Frequencies of diseases of the locomotor system among insured horses 1973-1981).Sven. Vet. Tidn., 1983, 35 (Suppl. 3), 14-20.

Brokken TD: Tarsal lameness in Thoroughbreds. Diagnostic and prognostic aids. Proc. 24th Conv. Amer. Ass. Eq. Pract., St Louis, Missouri, 1978, 341-343.

Butler JA, Colles CM, Dyson SJ, Kold SE, Poulos PW: Clinical radiology of the horse. Oxford, Blackwell Scientific Publications, 1993, 211-245.

Dahn $M$, Ueltschi $G$ : Étude de l'image radiologique du tarse equin normal (Radiologic study of the normal equine hock).Schweiz Arch. Tierheilkd. 1989, 131, 165-175.

Gabel $A A$ : Lameness caused by inflammation in the distal hock. Vet. Clin. North. Am. Large Anim. Pract., 1980, 2, 101-124.

Hartung $K$, Munzer B, Keller $H$ : Radiologic evaluation of spavin in young trotters. Vet. Radiol., 1983, 24, 153-155.

Hosmer DW and Lemeshow S: Applied logistic regression. New York, John Wiley \& Sons, 1989, pp 31, 44, 56-58.

Lindberg $S$ : Personal communication, Swedish Registry of Icelandic Horses (Svenska Islandshästföreningen), Box 167, 448 24, Floda Sweden, 1998.

May SA, Wyn Jones G, Peremans KY: Importance of oblique views in radiography of the equine limb. Equine Vet J, 1986, 18, 7-13.

Morgan JP: Radiology in Veterinay Orthopedics. Philadelphia, Lea \& Febiger, 1972, 193-196. 
Moyer W: Bone spavin: a clinical review. J.Equine Med. Surg., 1978, 2, 362, 370-371.

Moyer W, Brokken TD, Raker CW: Bone spavin in Thoroughbred race horses. Proc. Conv. Amer. Ass. Eq. Pract., Las Vegas, Nevada, 1983, 29, 8187.

$O$ 'Brien TR: Radiographic interpretation of the equine tarsus. Proc. Conv. Amer. Ass. Eq. Pract., Atlanta, Georgia, 1974, 289-300.

Odenhall T: Personal communication; Agria Insurance (Försäkringsaktiebolaget Agria), Box 70306, 10723 Stockholm, Sweden, 1996.

Rooney JR: Biomechanics of lameness in horses. Baltimore; Williams \& Wilkins Co., 1969, 211218.

SAS Institute Inc.: JMP 3.2, Cary, NC, USA, 1995.

Schebitz H: Spavin: Radiographic diagnosis and treatment. Proc. Conv. Amer. Ass. Eq. Pract., Miami Beach, Florida, 1965, 207-222.

Shelley J, Dyson $S$ : Interpreting radiographs. 5. Radiology of the equine hock. Equine Vet J, 1984, 16, 488-495.

Stashak TS, Kainer RA, Lebel JL, Lewis LD, McIlwraith $C W$, Nixon AJ, Park RD, Turner AS: In: Adams' (ed.): Lameness in horses. Philadelphia, Lea \& Fabiger, 1987, 694-704.

Thrall $D E(E d)$ : Textbook of veterinary diagnostic radiology. 2nd Ed. Philadelphia, W.B. Saunders, 1994, 157.

Vaughan JT: Analysis of lameness in the pelvic limb and selected cases. Proc. Conv. Amer. Ass. Eq. Pract., Miami Beach, Florida, 1965, 223-241.

Verschooten F, Schramme M: Radiological examination of the tarsus in horses. Equine Vet. Ed., 1994, 6, 323-332.
Watrous BJ, Hultgren BD, Wagner PC: Osteochondrosis and juvenile spavin in equids. Am. J. Vet. Res., 1991, 52, 607-612.

Wyn Jones G: Equine lameness. Oxford, Blackwell Scientific Publications, 1988, 302, 140-149.

\section{Sammanfattning}

Prevalens och riskfaktorer för benspatt på Islandshästar i Sverige: En radiografisk fältstudie.

Denna fältstudie utfördes i syfte att uppskatta prevalensen av radiologiska tecken på benspatt samt för att utvärdera några riskfaktorer för radiologiska tecken på benspatt på Islandshästar i Sverige. Studien inkluderade 238 valacker, 125 ston och 16 hingstar, inalles 379 hästar från 11 stall. Medelåldern var 8.1 år och varierade mellan 0-19 år. Hästarna undersöktes röntgenologiskt med en dorsolateral-plantaromedial projektion av vardera has. Data samlades in med hjälp av inspektion (haskonformation och kroppsbyggnad) och mätning (mankhöjd) av hästarna samt genom intervju med hästägarna (ålder, kön, arbetsnivå, ursprungsland, gångarter och inridningsålder). Radiologiska tecken på benspatt konstaterades på $23 \%(n=88)$ av hästarna. Hästar yngre än 5 år visade inga radiologiska tecken på benspatt och prevalensen ökade från 0 till 33\% mellan 4 år och 8 år. Vid multipel logistisk regression var stigande ålder och krokhasighet signifikant associerade med ökad risk för radiologiska tecken på benspatt. Inridningsålder tillsammans med mankhöjd påverkade också multivariatmodellen signifikant.

(Received May 21, 1997; accepted April 15, 1998).

Reprints may be obtained from: P. Eksell, Department of Clinical Radiology, Faculty of Veterinary Medicine, University of Agricultural Sciences, Box 7029, S-750 07 Uppsala, Sweden. E-mail: Per.Eksell@klra.slu.se, tel: +46-18 671487 , fax: +46-18 672811 . 